\title{
An Overview on the Integration of Large-Scale Wind Power Into the Electric Power System
}

\author{
R.P.S. Leão ${ }^{1}$, T. Degner ${ }^{2}$, F.L.M. Antunes ${ }^{1}$ \\ ${ }^{1}$ Department of Electrical Engineering \\ Federal University of Ceará \\ Caixa Postal 6001 Campus do Pici Fortaleza-CE (Brazil) Email: rleao@dee.ufc.br; fantunes@iset.uni-kassel.de \\ ${ }^{2}$ Institut für Solare Energieversorgungstechnik - ISET \\ Königstor 59 D-34119 Kassel (Germany) \\ tdegner@iset.uni-kassel.de
}

\begin{abstract}
As the wind power technologies evolve from one to another breakthrough and the wind power plants continue its ever increasing penetration in the power system it is a matter of time when the wind power production will be comparable to or even larger than the conventional power generation. In this paper the growth and advances of the wind power industry are described. Relevant aspects related to large-scale integration of wind power into the power system are discussed as the challenges arising from market liberalization, electricity networks innovation, the limited predictability of wind and the voltage and frequency control capabilities.
\end{abstract}

Keywords - Integration of wind power, wind-turbine generators' technology, dynamic evaluation, power quality.

\section{Introduction}

There has been a rapid increase in wind turbine connection to distribution and transmission networks in the recent years, and the increased penetration makes the power network more dependent on, and susceptible to, the wind energy production.

With individual wind turbines approaching the multiMW and the wind generation facilities, as a result, approaching the output rating of conventional power plants, a deeper understanding of their potential impacts on the interactions with the bulk electric power system is needed.

In this paper an overview on the state-of-the-art of the wind power technologies, the challenges faced by the wind turbine manufacturers and power system operators, and relevant features for performing dynamic studies on wind power integration are presented.

This paper is organized in six sections. Section 2 shows the penetration figures of wind power in the electric power system among individual countries. Then, in Section 3 a brief outline of common wind generation technologies is given and the advances of the wind power technologies are presented. In Section 4 the challenges faced by the wind power sector is discussed. Considerations on important aspects when performing dynamic studies on wind power integration such as wind turbine models, simulation tools and validation of the model are given in section 5. Finally, in Section 6 the paper conclusions are presented.

\section{The Wind Power Development}

The contribution from wind power in a global electricity context, at the beginning of 2006, stands at 59,322 MW. Around $70 \%$ of the world wind power capacity is installed in Europe. By the end of 2005, wind energy has achieved the European Commission's target for 2010, five years ahead of the time.

Wind power plays a significant part in the power production mix of Denmark, Germany, Spain, and some other countries. Denmark today has the highest wind power penetration level in the world - during off-peak situations, wind power can reach such a high penetration level that it can meet the total Danish demand. Germany leads the world in installed wind power capacity most of that is located outside the load centers. Currently (2006) wind power contributes about 20\% of Denmark's total power and $6 \%$ of the total Germany power supply. Due to the continuing high growth rate, Spain now has more than $10 \mathrm{GW}$ of installed wind power [1].

More than $67 \%$ of the world market for wind energy plants is shared by European manufactures, about $18 \%$ by the USA manufactures and $6.1 \%$ by suppliers in India [2]. Nowadays, the large manufacturers of wind turbines in the world market have attempted to expand towards new markets as in Asia, Latin America and Caribbean countries, and the demand for installation of wind power plants in these countries has grown. Asia registered strong development, mainly driven by the markets in India and China.

The present and progressive scale of integration has brought to a head serious concern about the impact of such a scale of wind penetration on the future safety, stability, reliability and security of the electricity system. 


\section{Moving Forward in Wind Technologies}

Wind power is the most promising and mature technology among the non-hydro renewable energies. The increase installed capacity of wind power is related to a fast development of new technology with advances in generators, mechanical drive train designs, blade materials and aerodynamics, controls of gearboxes and wind turbines and power converters breakthroughs which allowed machines to improve in performance and grow more and more in power capacity [3].

\subsection{Wind Turbines Concepts}

Basically two concepts of wind turbines dominate the market: the fixed-speed wind turbines with the generator connected directly to the grid and the variable-speed wind turbines with a power electronic converter (PEC) connected between the generator and the grid.

A fixed-speed wind-generator is usually equipped with a squirrel-cage induction generator whose speed variations are very limited. This configuration uses capacitor bank for reactive power compensation and has gearbox to match the rotational speed of blades with that of the generator. Mechanical power may be regulated through an inherent aerodynamic stall characteristic of blades or with active control of blade pitch.

A variable-speed wind turbine generator runs in its own, decoupling electrical grid frequency and mechanical rotor frequency. There are different concepts for the variablespeed wind generators: a) wound rotor induction generator with dynamic slip control, connected through power electronics to a variable resistance. This configuration can be described as semi-variable speed wind turbine with a speed range of up to $10 \%$ above synchronous speed. The variable speed conditions are achieved dissipating the energy within a resistor placed in the rotor [4]; b) direct driven (gearless) multi-pole synchronous generator connected to the grid through full size PECs. The frequency converter performs the reactive power compensation and allows variable speed operation over a wide range [5]; c) doubly fed induction generator, i.e. a slip-ringed wound-rotor induction generator, where a PEC is connected between the rotor circuit and the grid, this means that only the slip power is handled by the inverter and the rating of the inverter is often only $20 \%-$ $30 \%$ of the generator rating. They have variable speed operation depending on the rating of power converters relative to turbine rating. The ratio between the size of the converter and the wind turbine rating is half of the rotor speed span (e.g. $\pm 20 \%$ or $\pm 30 \%$ of generator synchronous speed) [4]. The smaller frequency converter makes this concept attractive from an economic point of view. Except the direct driven multi-pole synchronous generator all the other configurations are gearbox coupled wind turbines [6].

The fixed-speed and the semi variable-speed induction generators are part of the first-generation of wind turbines. Because of lacking controls on active and reactive power, the fixed-speed wind turbine technology is giving way to variable-speed drive machines. The control flexibility offered by static converters in the variable-speed wind turbines make possible independent active and reactive power control exchanged between the machine and the grid with better use of the available wind energy and higher power production as the wind turbine can rotate at the optimal rotational speed for each wind speed, and the grid voltage control as the reactive power generation can be varied. Active power of a variable-speed generator controlled electronically by fast power electronics converters reduces the impact of windfluctuations to the grid. In general, no flicker problems occur with variable speed turbines. It also keeps the harmonic contents injected into the grid by the power converter at low level improving the quality of the energy injected into the public grid. As disadvantages, variable speed wind turbines need a power converter that increases the component count, cost and make the control more complex. The overall cost of the power electronics is about $7 \%$ of the whole wind turbine [4].

The modern machines based on variable speed offer much better grid integration since they use a connection method similar to conventional power plants and also achieve a higher utilization degree. The two most-widely used variable-speed wind-generator concepts are doublyfed induction generators (DFIG) and multi-pole synchronous generators as depicted in Figures 1 and 2. These wind turbines are equipped with a pitch control system that enables them to: improve the dynamic behavior of the turbine; reduce drive train stresses, partially damp the mechanical power variations and the resulting voltage variations; limit the mechanical power on the main shaft of the wind turbine generator during voltage dips to help the wind farm to withstand it; limit the mechanical power on the main shaft of the wind turbine generator controlling mechanical speed, and hence the active power delivered to the network, to the maximum active power the wind turbine generator can withstand.

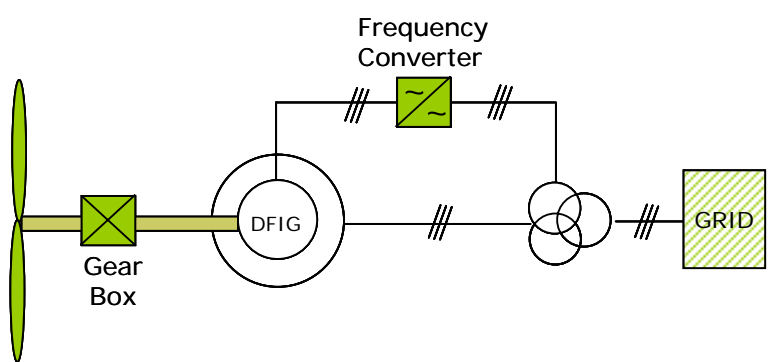

Figure 1 Wind Turbine with Doubly-Fed Induction Generator

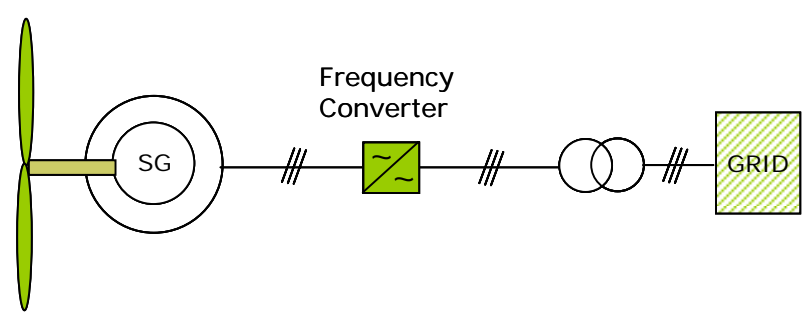

Figure 2 Wind Turbine with Multi-Pole Synchronous Generator

\subsection{Innovations in Wind Turbines' Technology}

Despite of the phenomenal growth and improvement in the last three decades, the wind power industry continues 
moving ahead to achieve cost effectiveness. As many of the most desirable high wind speed sites have been developed in Europe and the amount of land suitable for new wind turbine installation is ever decreasing, the wind power sector is moving to the replacement or repowering of the first-generation small wind turbines with modern multi-megawatt machines.

To achieve cost effectiveness the repowering program considers the application of taller tower to take advantage of higher winds aloft to increase energy capture [7]. As a matter of fact at levels higher than 100 meter above the ground the atmospheric boundary layer is much different than near the ground and new research into the turbulent environments and new simulation models are needed [8]. So far the highest tower is in Germany with a $160 \mathrm{~m}$ high, onshore, lattice type, with a $2.5 \mathrm{MW}$ variable-speed doubly-fed wind turbine. The advantage of lattice towers is primarily that they are lighter and cheaper [9].

New turbine designs of much greater size are being considered for offshore deployment in shallow and even deep waters in both Europe and the United States, where the offshore design environment is quite different than for land-based turbines [8]. Machines that are designed for offshore use should be large enough to satisfy offshore economics ( $>3 \mathrm{MW}$ ). Increases in machine size have effects on mass increasing, land transportation and turbine erection costs, as so innovations on design and materials have to be explored to reduce the related costs.

The development of multi-MW permanent-magnet (PM) synchronous generators has a strong appealing for offshore application with the decrease in cost and increase in availability of rare earth permanent magnets. The permanent magnet material has a magnetic flux density close to that of an electromagnet, which is achieved without the additional mass, size, and cost of the copper windings required for an electromagnet. This allows the creation of multi-pole smaller generators [8]. These generators are brushless and gearless, an important condition for offshore application with several benefits: reduced losses, increased reliability and lower maintenance cost. A hybrid concept is under way for PM generators that combine a smaller number of poles generator with a single-stage gearbox. The approach reduces the size of both the generator and the gearbox.

Innovations are also expected in power conversion techniques. Critical issues related to power conversion in variable-speed wind power systems are to maintain high efficiency over a wide range of wind speeds. Conventional converters are not optimized for variable speed wind power applications. Power converters achieve their highest performance at rated power. They present poor efficiency at low wind speed which means reduced energy capture. New power converter topologies are being investigated for the next generation wind turbines. Multilevel power converters can address the issues of variable speed wind power. Multilevel switching based on silicon switches enables to reduce the switching loss with improvement of the low-wind efficiency of the converter, without sacrificing performance at rated power [10].

Advances in power electronics will allow variable-speed generators to increase the overall efficiency of the electricity supply, Emerging Silicon Carbide based power electronic devices so far very expensive can be applied on wind power converters. Power converters based on silicon carbide ( $\mathrm{SiC}$ ) power switching technologies can achieve high power density and ultra-lightweight. SiC converter technology is more efficient than silicon and offers reduced weight and volume. While one advantage of $\mathrm{SiC}$ technology is to achieve higher power densities through high temperature operation, the other utilization of the technology is to operate in high temperature environments.

The power electronics technology plays an important role not only to the renewable energy source itself but also to its effects on power system operation and it is widely used and rapidly expanding as distributed generation and renewable energy sources become more integrated into the electrical grid. Wind turbine generators connected to the grid through power electronic interfaces can directly participate in the reactive compensation and voltage control. The reactive power provided or consumed by these wind generators is limited by the current limitation of the converters and thus their rating. Additional devices might be needed when the specific wind turbines used cannot meet the requirements by themselves. Static Var Compensators (SVA), Thyristor-switched Capacitor, and STATCOM and its variant D-STACOM are power electronic based devices that can typically provide much faster control and with lower losses than the traditional compensators such as synchronous compensators, fixed capacitor banks, inductors, fixed reactors, generators coupling transformer taps, and transformer tap controllers [11]. Several reactive power compensation facilities have been proposed in literature for voltage control and power flow control [12], [13], [14], [15].

\section{Wind Power Integration Challenges}

Large-scale wind generation facilities have become a very noticeable component of the interconnected power grid in many countries. The large integration can occur in two main conditions: large wind farms connected to the transmission system or several small wind farms are connected to the distribution systems in one area of the power system.

One of the major challenges faced by the electricity industry is how to effectively integrate significant amount of wind power into the electricity system. For a successful integration the electricity industry has to deal with challenges arising from market liberalization, electricity networks renewal and innovation, the limited predictability of wind and the frequency and voltage capabilities [3].

\subsection{Liberalized Electricity Market}

In the last decade many countries have started the process of liberalization of their electric systems, opening access 
to transmission and distribution grids. The process has encouraged the growing presence of distributed generation and the integration of renewable energy sources with the increasing number of players involved in the electricity supply. As energy markets are liberalized, individual consumers win the right to select their energy suppliers playing an active role in the supply chain, and on-line energy-trading markets develop. In this new market environment, a new electricity system model is envisaged that will not only remove all barriers to the deployment of new technologies, but a system capable of exploiting and optimizing the multiple benefits of all the new generation alternatives. In the future electricity network the distribution grids will become active and will have to accommodate bi-directional power flows. As distribution networks become more active and share many of the responsibilities of transmission, there will be less of a distinction between these network types. Intelligence will be distributed throughout the network which will allow real-time pricing schemes and on-line settlements of contracts, making the operation of energy suppliers and consumers aware of a more complete and wider market context. The market for energy should be supported by a stable and clear regulatory framework to provide consumers with a highly reliable, cost-effective power supply, fully exploiting the use of both large centralized generators and smaller distributed power sources [3], [16].

\subsection{Innovation of the Electricity Network}

One of the major issues of wind power integration is related to modification of the transmission infrastructure. The increase in generation connected to the grid, a sustained decrease in transmission infrastructure investments over the last two decades, and long delays in siting and approval of new transmission lines has exacerbated the problem considerably.

It is fully agreed that the transmission infrastructure in Europe, USA and in many parts of the world has ageing assets. There is a need for investment in end-of-life grid renewal, grid reinforcement and grid extensions.

Offshore wind energy is being taken increasingly seriously by energy sector and large wind turbine manufactures. In order to connect remote high-resource sites such as offshore to the load centers, new lines have to be constructed. Transmission of electricity makes up around one third of the cost of an offshore wind power plant. Voltage source inverter based HVDC transmission systems can connect the wind farms to the grid and transmit the power securely and efficiently to the load centers. This new technology does not require the offshore AC grid to be powered up prior to start-up (black-start capability) [4]. In the longer term, a European super-grid is proposed to accommodate large amounts of offshore wind power and to utilize continental-wide smoothing effects of wind power to a maximal extent [17].

Of the challenges facing utilities, possibly the most urgent is the issue of eliminating transmission constraints and bottlenecks. Transmission bottleneck is a relatively new problem for the wind power field [11], [18]. In areas where the transmission system is not dimensioned to accommodate additional large-scale power in-feed some provision has to be taken in order to handle grid congestion and operation constraints violation. Some considered alternatives for large-scale wind power integration in areas with transmission bottlenecks are the transmission network reinforcement and expansion, wind power curtailments and excess of wind power storage. Wind power production depends on the wind speed, and the full load hours of wind turbine generator are only 2000-4000 hours per year which means that the wind turbines operate far below their power rating (30\% to $40 \%$ ) a majority of the time and wind power production peaks do not necessarily occur during the periods with insufficient transmission capacity. Therefore reinforcing a transmission network in order to remove a bottleneck completely is often not economically justified. Wind power curtailments during congestion situations are another solution for large-scale wind power integration with less or no grid reinforcement. The risk of curtailment is seen as a barrier to securing financing for future investment in wind generation. Curtailment of electricity production should be managed according to least-cost principles from a complete system point of view [17]. A third solution is to consider coordination of wind power with power plants existing in the same area to store excess wind energy. Hydro power plants and gas fired power plants have fast production control capabilities that make it possible to set up a short term power production planning method. The fast-controllable hydro and gas fired based power plants can also be used as real-time balancing power for areas where a large part of electricity generation is provided by non-controllable primary energy as wind energy [3]. When the fastcontrollable power plants are outside the wind power area the system balance can be ensured by expanding and increasing interconnection capabilities.

There is general consensus that the future power grid will need to be smart, fault tolerant and self-healing, dynamically and statically controllable, and asset and energy efficient [3], [15], [16]. New network technologies that facilitate increased power transfers on the grid including voltage regulation, system damping and power flow control have been through by the use of Flexible AC Transmission Systems or FACTS [12]. A new class of distributed FACTS or D-FACTS devices has been proposed in [15] for realizing active power flow control on an interconnected power system by using light-weight selfexcited modules that float on the power line.

\subsection{The Variability of Wind Power Output}

Some fears about interconnection of wind power plant are still voiced by many transmission system operators and utility engineers. A major fear is related to the variability of the wind plant output. It is sometimes incorrectly expressed that wind energy is inherently unreliable because it is variable - wind is variable but far from unpredictable. The limited predictability of wind is however a challenge although variability in electricity is nothing new. Both electricity supply and demand are variable. A large geographical spread of wind power will 
reduce variability, increase predictability and decrease the occurrences of near zero or peak output. Geographical averaging is a powerful fact that smoothes variations in wind energy output at all time-scales [17]. Studies show that for an individual wind turbine, the variation in output is small for time-scales of less than a few seconds; for an individual wind farm, the variation in output is small for time scales of tens of seconds, due to the averaging of output of individual turbines across the wind farm; and for a number of wind farms spread out across a large area, such as a national grid system, the variation in output of all wind turbines is small for timescales from minutes to tens of minutes. The power produced from a large number of wind turbines will vary relatively less than the power produced from a single wind turbine due to the cancellation effect from the poor spatial correlation of the wind acting on each wind turbine.

\subsection{Low Voltage Ride-Through and Frequency Capabilities}

To enhance the security of supply, new transmission and distribution grid codes specify technical requirements such as fault-ride through capability and frequency control of the electrical conversion systems of wind farms. Fault ride-through capability refers to the generators capabilities to remain connected to electricity networks at voltage levels below nominal. Active power control is closely related to frequency control and the wind farm shall have frequency control capabilities to ramp up and down the wind farm power station's active power output in accordance with the frequency/active power characteristic defined by the grid operator [19].

The low voltage ride-through capability required for wind plants at point of common coupling are $20 \%$ of the rated voltage in Spain, 15\% in the Republic of Ireland and $0 \%$ in Germany, England \& Wales, Scotland, France and Denmark as shown in Figure 3, with different time delays [19], [20], [21].

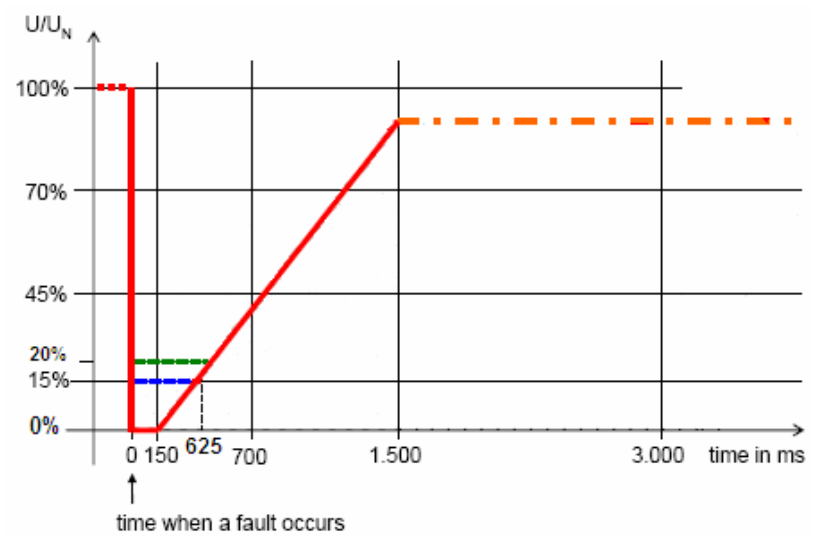

Figure 3 Wind Turbines Low Voltage Ride-Through Capability

When a power system is subjected to a sudden increase in reactive power demand following a system disturbance, the additional demand must be met by reactive power reserve carried by generators and compensators. If wind farms or other generation units are unable to withstand voltage drops for a limited time, they will disconnect from the system and then the reactive power supplied by these generators is lost that can entail load shedding or even a blackout, in the worse case [20]. To ensure the voltage recovery the wind-turbine generators must remain connected to the system to provide reactive power support after the fault clearance. For many wind turbine manufacturers these are very costly and challenging requirements. In some cases extensive modifications to the electrical system of the turbines are necessary [22].

Achieving reliable operation at greatly reduced voltage levels is proving problematic. A particular problem regarding power converter-based wind-turbine generators is that conventional controllers for power converters designed for reliable operation around nominal voltage levels will not work as designed during low network voltages that can occur during a fault. A consequence of this is greatly increased converter currents, which may lead to converter failure. New controller design strategies have been proposed for power converter-based wind turbine generators aiming to maintain converter currents within their design limits, even at greatly reduced voltage levels, in order to enhance the wind-turbine generators' fault ride-through capability [23], [24].

With the increasing penetration of power converter-based wind turbine generators the rotational speed of the wind turbines are decoupled from the grid leading to a reduction of inertia in the grid. The lower the inertia of a system, the more and faster the frequency will change with variations in generation or load. In order that a variable-speed wind turbine to contribute to the system inertia and the frequency control as a result it has been proposed in [25] an additional control loop in the power electronic converter which connects the turbine inertia directly to the grid so that the wind turbine will be able to increase its power supplied to the grid during a drop in the grid frequency.

Whilst the wind farms are considered like other generating facilities by some grid operators and as such they are requested to participate in the system frequency and voltage compensation, the wind power sector claims for less strict requirements which imposes unnecessary burden and cost on manufacturers. The wind power sector calls on an overall economically efficient solution where the primary and secondary control should be provided by conventional power plants with the wind farms providing such service only in cases where limits in existing reserves are foreseen, and reactive power compensation provided by FACTS devices directly installed in the transmission network [17].

\section{Dynamic Interaction of Wind Power Penetration}

\subsection{Impact of Wind Power Plants on Power System Transient Stability}

One of the major concerns related to the high level penetration of the integrated wind turbines is the impact on power system stability. Power system stability is concerned with transient angular stability and transient voltage stability. Transient angular stability studies typically evaluate generator frequency and internal angle 
to determine if the system remains stable after a disturbance. Voltage stability studies determine bus voltage profiles in the system before, during, and immediately after a major disturbance. In examining voltage stability it must be ensured that the voltage can recover to within normal limits. To achieve angular and voltage stability the main issues are torque control and voltage recovery. From the point of view of mechanical torque control, turbines equipped with a pitching system have the advantage of actively controlling down the input mechanical torque by pitching, which will effectively limit the acceleration of the generator system. From the generator sides, a quick recovery of voltage and reestablishment of the electromagnetic torque are crucial.

Large disturbances such as short circuits in sites with large amount of wind turbines can result in voltage transient instability due to the limitation of reactive power transfer and the huge demand from the induction generators as well as transformers after the fault is removed. The inability of a power system to meet reactive power demand will cause voltage instability, with the risk of eventual voltage collapse [26].

In some particular cases, the frequency can be affected by the wind turbines. The large active power variations can interact with the frequency controllers in the conventional power stations, and frequency variations can happen.

In order to obtain an optimal integration of wind energy in the system, the large wind farms must be able to withstand network disturbances that are successfully eliminated i.e., be able to participate in the control and stabilization of the power system following system disturbances. In the previous sections some compensation devices and control approaches have been considered to ensure a secure and optimized integration of wind power plants.

As stated in [17], R\&D should continue to further improve the knowledge on dynamic interaction of system and wind power plants.

\subsection{Relevant Aspect for Power Wind Integration Evaluation}

There are key aspects to take into consideration when performing dynamic studies on wind power integration, such as:

- Wind turbine and wind facilities models for dynamic analysis. The development of good quality models will assist the operation of the power system and will lead to a better understanding of the impact of wind on the transmission systems' angular and voltage transient stability and also aid in the prevention of transient voltage collapse and transient angular instabilities;

- Simulation tools to carry out studies to assess the dynamic impact of high levels of wind generation on the system; and

- Validation of the model to give confidence in the results of the dynamic simulation.

\section{A) Wind Power Simulation Models}

Dynamic models of wind turbine generators are computer software based on a mathematical representation of the turbines' behaviour. The models of the wind turbine generators should take into account the inherent characteristic of the machines and the actions of the wind turbine generators control systems and any relevant wind farm power station control systems. The purpose of the model is to enable assessment of power quality, control strategies and behavior of the wind turbine during normal operation and in the event of grid faults. In order to reflect a real wind farm as closely as possible a wind farm must be represented fairly. The method of analysis used to measure the characteristics of a wind farm plays an important role in determining the final conclusion.

Wind power plants exhibit static and dynamic characteristics that differ fundamentally from that of conventional generators and as a result, they do not fit the template for models of conventional generating facilities. Most of the wind turbines elements have counterparts in conventional electric generation systems but differ greatly in their implementation details. The prime mover in wind turbines consists of power extracted from the wind, which is converted to rotational mechanical power via the aerodynamic properties of the turbine blades. The conversion of aerodynamic power to mechanical torque is a unique aspect of wind turbine operation. Mechanical power is transmitted through a drive train, usually containing a gearbox to match the slow rotational speed of the blades to the much higher speed needed for the electrical generator to produce output at the grid frequency. The drive train has the most significant influence in the power fluctuations, power quality and transient stability.

To investigate the wind power influences on the power system quality and stability it is imperative the use of appropriate models to represent the wind farm and the power system. Improved models for wind turbines and wind plants are an important element of the overall solution to the transmission challenges facing wind generation in most countries.

The integration of wind power has been restrained by the lack of suitable dynamic models for use in transient stability programs. System modeling for stability analysis purposes is one of the most critical issues in the field of power system analysis. The number of different turbine technologies used increases the complexity of the modeling problems. Models with varying levels of detail have been developed for various different wind turbine generators. There is concern that the current models may be too complex. It is important to have as simple models as possible that still manage to model the dynamics of interest.

It is agreed by the wind industry and the power sector that all aspects of dynamic interaction of system and wind power plants not yet fully understood and continued research work is needed to improve the dynamic models for the latest wind turbine types for investigating 
dynamic interaction between wind farms and power system [17].

In order to facilitate the addition of wind power, while safeguarding system security for all electricity customers, the Irish electric power transmission operator, EirGrid, requires that the wind turbine manufactures provide the dynamic model in compliance with the national grid code of all wind farms greater than $5 \mathrm{MW}$ before granting connection to the transmission and distribution permits. The transmission operator makes publicly available on the website the current status of the wind turbine generator dynamic models and the work which still remains to be done by manufacturers.

\section{B) Simulation Software Packages}

There are a number of commercial simulation programs widely used by power-system operators to study load flow, steady state voltage stability, dynamic and transient behavior of power systems. Most of these packages provide a comprehensive library of models of electrical components in power systems. The grid model and the electrical components of the wind turbine model are included as standard components in the existing library. However, so far there are no suitable library models available for the non-electrical wind turbine generators components. The models of the wind speed required for simulate the spatial effect of wind behavior, the mechanical system, the aerodynamic system and the control systems of the wind turbines, and spatial aggregation models for the wind turbines in a wind farm are especially written models provided by the software user. The many different conceptions of wind turbine systems with different types of controllers result in an extra burden to the planners and operators of the power system [27].

Simulation of the wind turbine interaction with the grid may provide valuable information and may even lower overall grid connection costs. The interaction between the mechanical structure of the wind turbines and the electrical grid during different operational modes enable both the wind turbine investors and the grid utility technical staff to perform the necessary preliminary studies before investing and connecting wind turbines to the grid.

The most used commercial software packages for analysis of wind turbines design and to simulate the integration of wind generation to the power system are: MATLAB/Simulink, SABER, PSS/E, PSLF, PSCAD/EMTDC, EMTP-RV, DIgSILIENT PowerFactory, SIMPOW and EUROSTAG. The tools may be used for different focused simulations. Some packages are capable of performing steady-state and stability analysis of large-scale power systems with thousands of buses. To cope with this situation the models must not require a small simulation time step, often no less than $5 \mathrm{~ms}$. A very small integration time step can result in long time periods for simulations to run. On the other hand, some simulation packages such MATLAB/Simulink and SABER, are more suitable to represent in more details the design of the wind turbine power converters and controllers. These simulation platforms are capable of performing dynamics studies of small power system and are used to observe the effect of different types of control strategies. The detailed models often are made simpler and their responses under different system operation conditions are evaluated using the simulation tools conceived for large systems.

PSCAD/EMTDC, $\quad$ EMTP, DIgSILENT, MATLAB/Simulink and SABER are simulation tools that capture individual phase and point-on-wave phenomena. PSS/E and PSLF have become the de facto standards for the majority of power system studies in North America and use simplified positive-sequence models [5].

Advances in simulation tools will greatly assist operators and planners of the electric power systems bound to evaluate and to assure the reliability, power quality and stability of the power system with the integration of new technologies for generation.

\section{C) Model Validation Procedures}

All models for use in dynamic simulations must be validated in order to give confidence in the results of the dynamic simulation.

The predicted behavior of the dynamic model must compare with the actual observed behavior of a prototype or production wind turbine generator under laboratory conditions and/or a real wind turbine generator as installed and connected to a transmission or distribution network. For validation purposes the wind farm power station shall ensure that appropriate tests are performed and measurements taken to assess the validity of the dynamic model. The conditions validated should as far as possible be similar to those of interest, e.g. low short circuit level at Connection Point, close up, severe faults, nearby moderate faults, remote faults, voltage excursions, frequency excursions, large wind speed variations. There are essentially four types of behavior information: the behavior predicted by a model represented by the commercial software packages; the behavior predicted by the designers of the machine which may be based on a much more detailed and often complex model than the commercial software packages model and may contain confidential information not shareable with others; actual behavior of a prototype or production wind turbine generator under laboratory conditions; and, actual behavior of the real wind turbine generator as installed and connected to a transmission or distribution network. Comprehensive validation of the models through rigorous field or laboratory testing is generally lacking.

\section{Concluding Remarks}

In the last three decades a new scenario has emerged in the area of power systems with the participation of the wind power in the energy matrix in many countries all over the world. The wind power has caused many transformations compelling to re-thinking the planning 
and operational strategies of the power system, restructure the power grid, revise the grid rules, research on suitable and accurate models for the wind turbines, wind farms and the interaction with the power grid, development of new standards and simulation tools, and new demands and enlightenment on the electricity markets. And the evolution continues. The recent transformations have also driven to a new perception, motivation and admission of a young generation of engineers to the power system area. Many challenges and new breakthroughs are still under way, they are however the foundations to move forward successfully.

\section{Acknowledgments}

The authors would like to express their appreciation for the sponsorship from CAPES and CNPq, the Brazilian Research Financing Agencies. They would like also to acknowledge the Institut für Solare Energieversorgungstechnik - ISET in Germany for the discussions and friendship during the sabbatical year.

\section{References}

[1] Wind Energy 2006. Bundesverband WindEnergie e.V. www.wind-energie.de.

[2] International Wind Energy Development World Market Update 2005. Press Release. Source: BTM Consult ApS March 2006. http://www.btm.dk/world-index.htm.

[3] European Technology Platform SmartGrids - Vision and Strategy for Europe's Electricity Networks of the Future. European Commission. Directorate-General for Research. Directorate J - Energy. Unit 2 - Energy Production and Distribution Systems. 2006. ISBN 92-79-01414-5.

[4] J. M. Carrasco, E. Galván, R. Portillo, L.G. Franquelo and J.T.Bialasiewicz. Power Electronic Systems for the Grid Integration of Wind Turbines. Proceedings of the $32^{\text {nd }}$ Annual Conference of the IEEE Industrial Electronics Society. IECON'2006. November, 2006. Paris (France). pp. 4182-4188.

[5] R. Zavadil, N. Miller, A. Ellis and E. Muljadi. Making Connections. IEEE Power \& Energy Magazine. 2005, pp.26-36.

[6] P.B.Eriksen, T.Ackermann, H.Abildgaard, P.Smith, W.Winter and J.R.Garcia. System Operation with High Wind Penetration. IEEE Power \& Energy Magazine. 2005, pp.65-72.

[7] Repowering - more wind power with fewer wind turbines. German WindEnergy Association (BWE). http://www.wind-energie.de/en/topics/.

[8] R. Thresher and A. Laxson. Advanced Wind Technology: New Challenges for a New Century. European Wind Energy Conference Athens, Greece February 27-March 2, 2006.

[9] Highest WEC worldwide - Fuhrlaender AG. www.fuhrlaender.de.

[10]Bob Erickson. Future Directions in Wind Power Conversion Electronics. Colorado Power Electronics Center. University of Colorado, Boulder. ece.colorado.edu/ pwrelect.

[11] Pierre Bousseau, Floriane Fesquet, Régine Belhomme, Samuel Nguefeu and Thanh Chau Thai. Solutions for the Grid Integration of Wind Farms-a Survey. WIND ENERGY. 2006; 9:13-25.

[12] V. Salehi, S. Afsharnia, S. Kahrobaee. Improvement of Voltage Stability in Wind Farm Connection to distribution
Network Using FACTS Devices. Proceedings of the $32^{\text {nd }}$ Annual Conference of the IEEE Industrial Electronics Society. IECON'2006. November, 2006. Paris (France). pp. 4242-4247.

[13]Z. Chen, Frede Blaabjerg and Y Hu. Stability Improvement of Wind Turbine Systems by STATCOM. Proceedings of the $32^{\text {nd }}$ Annual Conference of the IEEE Industrial Electronics Society. IECON'2006. November, 2006. Paris (France). pp. 4213-4218.

[14] S. Bozhko, R. Li, R. Blasco-Gimenez, G. M. Asher, J. C. Clare, L.Yao, and C. Sasse. STATCOM-controlled HVDC Power Transmission for Large Offshore Wind Farms: Engineering Issues. Proceedings of the $32^{\text {nd }}$ Annual Conference of the IEEE Industrial Electronics Society. IECON'2006. November, 2006. Paris (France). pp. 42194224.

[15]D. Divan and H. Johal, Distributed FACTS - A New Concept for Realizing Grid Power Flow Control 36th IEEE Power Electronics Specialists Conference, PESC'05. 2005 Page(s):8 - 14.

[16] Manuel Sánchez Jiménez. Smart Electricity Networks based on large integration of Renewable Sources and Distributed Generation. Doctor Thesis. University of Kassel - Germany. Junho 2006. 158 pages.

[17] Large scale integration of wind energy in the European power supply: analysis, issues and recommendations. December 2005. Published by the European Wind Energy Association - EWEA. http://www.ewea.org.

[18] Matevosyan, Julija. Wind Power Integration in Power Systems with Transmission Bottlenecks. Doctoral thesis. Royal Institute of Technology. School of Electrical Engineering. Stockholm - Sweden, 2006..

[19] Grid Code Version 2.0 January 2007. Published by EirGrid. www.eirgrid.com. 265 pages.

[20] Discussion Document for the Review of Requirements for Wind Turbine Generators under System Fault Conditions, commonly referred to as Fault Ride Through. Published by EirGrid. 16/02/2004. www.eirgrid.com.

[21] Grid Code High and extra high voltage. Published by E.ON Netz GmbH, Bayreuth. $1^{\text {st }}$ April 2006. www.eonenergie.com. 46 pages.

[22] Fritz Santjer, Rainer Klosse, New Supplementary Regulations for Grid Connection by E.ON Netz GmbH. DEWI Magazin Nr. 22, February 2003. pp. 28-34.

[23] Alan Mullane, Gordon Lightbody, and R. Yacamini. Wind Turbine Fault Ride-Through Enhancement. IEEE Transactions on Power Systems, Vol. 20, No. 4, November 2005. pp. 1929-1937.

[24] J. Morren and S. W. de Hann. Ride-through of wind turbines with doubly-fed induction generator during a voltage dip. IEEE Trans. Energy Conversion Vol. 20, no. 2, pp. 435-441, Jun. 2005.

[25] Johan Morren, Jan Pierik, Sjoerd W.H. de Haan. Inertial response of variable speed wind turbines. Electric Power Systems Research $76 \quad$ (2006) 980-987. www.elsevier.com/locate/epsr.

[26]T.Degner, Jürgen Schmid, Philip Strauss. Dispower Distributed Generation with High Penetration of Renewable Energy Sources. Final Public Report. ISBN 300-016584-3. 2006.

[27] Dynamic Modelling of Wind Generation in Ireland, ESB National Grid Uptade on Progress and Status of Work. June/2005 and December 2006. 